\title{
Parametric Design and Motion Analysis of Geneva Wheel Mechanism Based on the UG NX8.5
}

\author{
En-guang Zhang* ${ }^{1, a}$, and Li Wang ${ }^{1, b}$ \\ ${ }^{1}$ Zhuhai College of Jilin University, China \\ a teamcenter@163.com ; b wangli00019@163.com
}

Keywords: NX8.5, Intermittent Motion, Motion Analysis ,Geneva Wheel.

\begin{abstract}
The movement characteristics and process cost of 4 intermittent motion mechanisms including ratchet mechanism, geneva wheel mechanism, cam mechanism and intermittent gear mechanism are comparatively analysed. According to the working principle of geneva, the parametric design and motion analysis are carried out using NX8.5. Analysis of the velocity, displacement and acceleration curves indicate that geneva mechanism has flexible impulse. So it is not suitable for high speed applications. This paper proposed that parametric design and movement simulation in NX8.5 can be seamless connected, the data is unified, and the connection can improve the efficiency of design and visual design.
\end{abstract}

\section{Introduction}

In many mechanical devices, the components show the periodic intermittent motions. For example, the clamping mechanism of the injection molding machine can be opened through maintaining the pressure for a period of time. The mechanism that shows this motion state is called the intermittent motion mechanism[1,2].

The intermittent mechanism has been widely applied in the assembly line, the liquid filling equipment and the packaging production line. The commonly-used ones refer to the geneva wheel mechanism, the ratchet wheel mechanism, the cam wheel mechanism and the intermittent gear mechanism. The structures and the motion characteristics of the four mechanisms are shown in Table $1[3]$.

Comparing with the four mechanisms, the noise of the ratchet mechanism is large and the precision is poor. The precision of cam is high and it can be controlled by various motion curves, but the processing requirements are relatively high; the impact of intermittent gear mechanism is large and the vulgar light load is required; comparatively speaking, the geneva wheel mechanism is widely applied in the automatic production line.

\section{Design of Geneva Wheel}

At present, many researchers have studied the design and the simulation of the geneva wheel and there are more and more engineering software that can realize the parametric design and the motion analysis of geneva wheel[4,5,6], such as Catia, NX and Pro/E, etc. NX8.5 is a three-dimensional digital software that integrates $\mathrm{CAD} / \mathrm{CAE} / \mathrm{CAM}$ with powerful functions. The function has covered the whole lifecycle of products, including the design, the assembly, the drawing, the advanced simulation, the motion simulation and the processing. The seamless connection can be realized in each module. The modeling module provides the tools of parametric design and the motion simulation module provides the kinematics and dynamics analysis. In this paper, NX8.5 is employed to conduct the parametric design and the motion simulation analysis for geneva wheel.

It is required to enter NX8.5 modeling module and establish the relevant expressions according to the calculation in Figure 1; the commands such as sketches, extrude and boolean operation are employed to establish the geneva wheel diagram, as shown in Figure 2. 
Table 1 Comparison of the four mechanisms

\begin{tabular}{|c|c|c|}
\hline Name of mechanism & $\begin{array}{l}\text { Structure and motion } \\
\text { characteristics }\end{array}$ & Representative mechanism \\
\hline Ratchet wheel mechanism & $\begin{array}{l}\text { The structure is simple that is } \\
\text { convenient to adjust the rotation } \\
\text { angle; there exist the large } \\
\text { impact and noise; the precision is } \\
\text { poor. }\end{array}$ & $\begin{array}{c}\text { Shaper table horizontal feeding } \\
\text { mechanism, one-way clutch or } \\
\text { overrunning clutch }\end{array}$ \\
\hline Geneva wheel mechanism & $\begin{array}{l}\text { The structure is simple, the size } \\
\text { is small, the mechanical } \\
\text { efficiency is high and it can be } \\
\text { stable and intermittent for } \\
\text { transposition. However, the } \\
\text { changes of the acceleration rate } \\
\text { in the process of motion is large } \\
\text { and there exists the flexible } \\
\text { impact, which is not applicable } \\
\text { to the high speed. }\end{array}$ & $\begin{array}{l}\text { Film feeding device of film } \\
\text { projector } \\
\text { Automatic transmission chain } \\
\text { device }\end{array}$ \\
\hline Cam wheel mechanism & $\begin{array}{l}\text { The structure is simple, the } \\
\text { operation is reliable and the } \\
\text { transmission is stable. The rigid } \\
\text { impact and the flexible impact } \\
\text { can be avoided. The additional } \\
\text { positioning device is not } \\
\text { required. The processing and the } \\
\text { assembly have high } \\
\text { requirements. }\end{array}$ & $\begin{array}{c}\text { Cog zipper machine } \\
\text { Match packing machine }\end{array}$ \\
\hline Intermittent gear mechanism & $\begin{array}{l}\text { The variation range of the time } \\
\text { angle is large and the design is } \\
\text { flexible } \\
\text { The process is complex, the } \\
\text { impact is large and it is suitable } \\
\text { for the light load with low speed. }\end{array}$ & $\begin{array}{l}\text { Intermittent transposition and } \\
\text { counting mechanism of the multi } \\
\text { station, multi process automatic } \\
\text { machine and semi automatic } \\
\text { machine working table }\end{array}$ \\
\hline
\end{tabular}

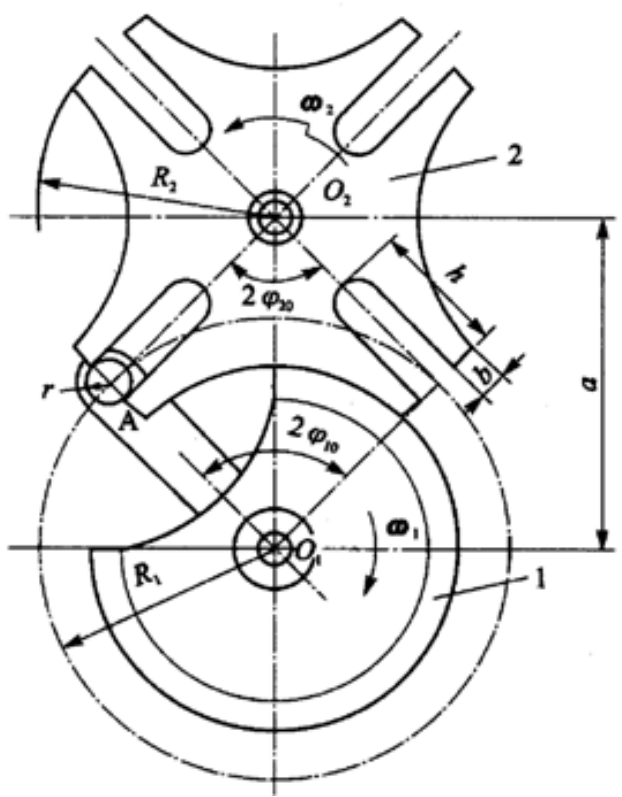

Figure 1 Size of geneva wheel

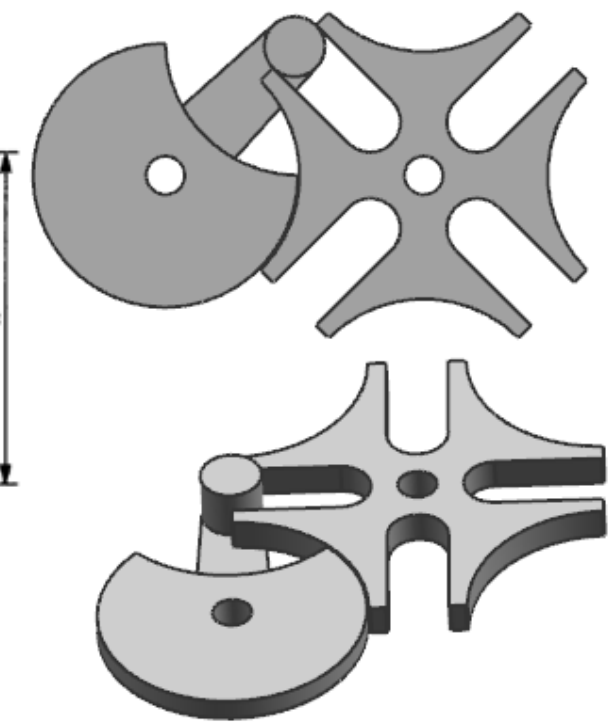

Figure 2 Model of geneva wheel

The number of geneva is $Z=4$, the distance from the geneva wheel to the center of the pin wheel is $\mathrm{a}=80 \mathrm{~mm}$ and the number of round pins is $n=1$. The calculation of the size and the parameters of geneva wheel mechanism is shown as follows: 


$$
\Phi_{2}=\frac{2 \pi}{Z}=\frac{2 \times 180^{\circ}}{4}=90^{\circ}
$$

The motion angle of the pin wheel that is corresponding to the geneva angle of the geneva wheel:

$\Phi_{1}=\pi-\Phi_{2}=90^{\circ}$

The gyration radius of the pin center: $\mathrm{R} 1=\mathrm{a} \sin (\pi / 4) \approx 56.6 \mathrm{~mm}$

The radius of the round pin: ${ }^{r} \approx \frac{R_{1}}{6}=\frac{56.6}{6} \approx 9.4(\mathrm{~mm})$

The excircle radius of the geneva wheel: $R_{2}=\sqrt{\left[a \cos \left(\frac{\Phi_{2}}{2}\right)\right]^{2}}+r^{2} \approx 57.4(\mathrm{~mm})$

The height of geneva roof: $\mathrm{H}=\operatorname{acos} \frac{\pi}{\mathrm{Z}} \approx 56.6(\mathrm{~mm})$

The length of the geneva wheel:

$$
b \geq R_{1}+r+H-a=56.6+9.4+56.6-80=42.6(\mathrm{~mm})
$$

The thickness of the side wall of the geneva roof:

$$
e=0.6 \times 9.4 \approx 5.6(\mathrm{~mm})
$$

The locked arc radius: $R_{X}=R_{1}-r-e=41.6(\mathrm{~mm})$

The open angle of the outer convex lock: $\gamma=2 \pi\left(\frac{1}{n}+\frac{1}{Z}-\frac{1}{2}\right)=270^{0}$

The coefficient of action: ${ }^{\tau=n} \frac{z-2}{2 z}=0.25$

The coefficient of action is less than 0.5 , which indicates that the motion time of the geneva wheel is always less than the rest time

\section{The Motion Analysis of The Geneva Wheel}

It is required to directly enter the motion simulation module of NX. The motion simulation module of NX can analyze the motion principle of the mechanism and the interference between parts as well as the displacement, the velocity, the acceleration rate, the force and the torque of the parts or the mass points in different reference systems.

Firstly, it is required to understand the working principle of the geneva wheel: 1 . Actively driving plate rotation; 2 . The cylindrical pin enters the radial slot; 3 . The locking arc is loosen; 4 . Driven geneva wheel rotation; 5 . Turning point of driver plate $2 \Phi 1 ; 6$. The geneva wheel is turned $2 \Phi 2 ; 7$. The cylindrical pin is disengaged from the radial slot; 8. Another locking arc of the geneva wheel is locked by the dial locked arc; 9. The driver plate is rotated and the geneva wheel is still.

Therefore, the motion analysis of the geneva wheel should use the "dynamic" environment. The active driver plate and the driven geneva wheel are respectively added the rotational pairs as well as the "3D contact" so as to ensure the stability of the motion. The "damping" is added into the rotating pair of the driven geneva wheel and the angular velocity as well as the angular displacement curve of geneva wheel are shown in Figure 4. From the continuity of the velocity and the displacement curves as well as the mutation of the acceleration curve, it can be seen that the geneva wheel mechanism has the flexible impact and it is not suitable for high speed applications.

\section{Conclusion}

Through the above examples, it can be seen that the parametric design of NX8.5 for the geneva wheel can greatly improve the design speed. The motion simulation module of NX can better achieve 
the application from the design to the simulation and intuitively show the motion process and the rules of geneva wheel mechanism. At the same time, the key motion parameters are analyzed and the seamless connection with the modeling module is achieved to greatly improve the design efficiency and ensure the unity of the data.

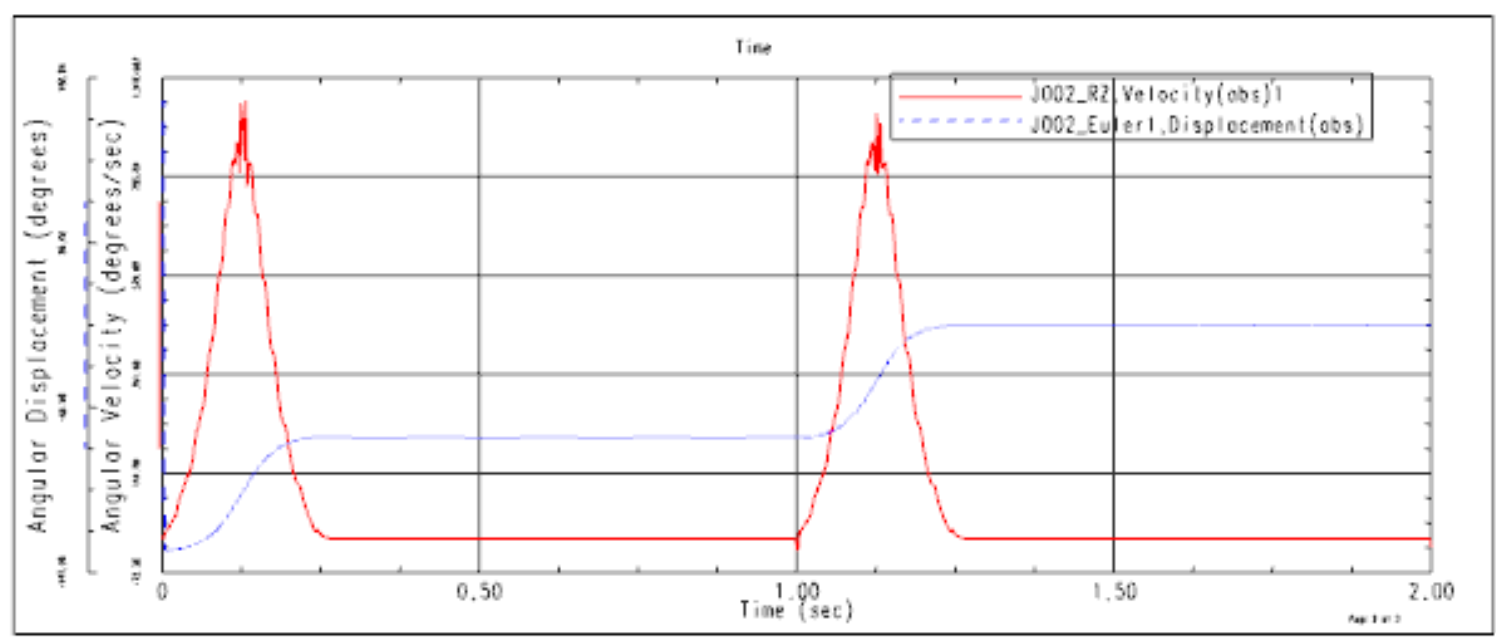

Figure 3 Angular velocity and angular displacement curves of geneva wheel

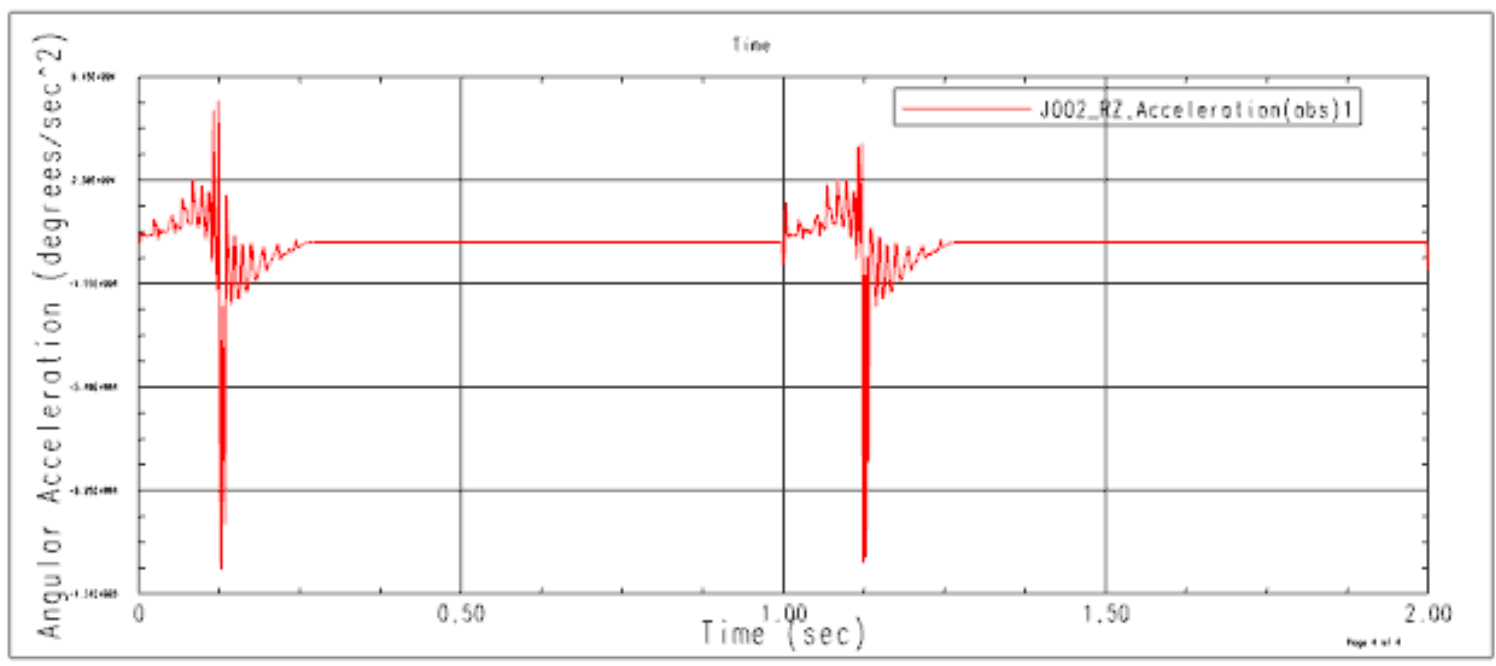

Figure 4 Acceleration curve of the geneva wheel

\section{Acknowledgement}

This research was financially supported by Zhuhai Premier-Discipline Enhancement Scheme of Vehicle engineering (Zhuhai College of Jilin University). ( Fund code: 2015YXXK14)

\section{References}

[1] X. Z. Han, Y.L. Zhang, Parametric design and motion simulation of grooved wheel mechanism, Machine Design and Manufacturing Engineering. 45 (2016) 40-43.

[2] Y. M .Guan., Incomplete gear-design and application of incomplete gear, Machinery Design \& Manufacture, 7 (2009) 59-61

[3] C. 1. Zhang, Mechanisms Theory, first ed., Higher Education Press, Beijing,2009, pp. 230-238.

[4] L. Zhang, Motion Analysis and Optimization Design of Geneva Mechanism, Science Technology and Engineering. 11 (2011) 4198-4200 
[5] H.T. Li, Design of a new kind of curved groove on geneva mechanism, Journal of China Agricultural University. 10 (2005) 62-65

[6] L. Zhang.Design and Research on a New Geneva Mechanism, Journal of Mechanical Transmission. 10 (2007) 36-39 